\title{
¿Dios es omnivolente?
}

\author{
Rafael Jiménez Cataño \\ Universitá della Santa Croce
}

As an introduction to Paul Weingartner's article "Religiöser Fatalismus und das Problem des Übels", some clarifications about propositional functions are made, especially functions regarding the will. Other cultural considerations about willing and allowing are offered.

Hace dos años apareció en la revista Analogía un artículo de Paul Weingartner, de la Universidad de Salzburgo", titulado "El fatalismo religioso y el problema del mal"2, que traduje yo. Mi propósito en estas páginas es hacer notar su existencia y facilitar la lectura con algunas observaciones introductorias. El artículo tenía más de treinta años, escondido en un volumen colectivo ya imposible de encontrar ${ }^{3}$. Sin embargo, es claro que para semejante tema el tiempo es irrelevante, y a eso se añadía que tampoco por el modo de tratarlo había perdido actualidad el artículo.

Me movió a traducirlo una conjunción de factores. Por una parte, es indudable el interés de una buena reflexión sobre el fatalismo religioso, que podemos caracterizar brevemente como la posición de quien piensa que todo lo que sucede Dios lo quiere. Un Dios asi sería "omnivolente", de la misma manera que se le llama omnisciente cuando se sostiene la tesis que reza asi: todo lo que existe, Dios lo conoce, y todo lo que sucede, Dios lo sabe.

\footnotetext{
${ }^{1}$ Actualmente es profesor emérito.

${ }^{2}$ Analogía Filosófica, año XVI (2002) N.1, pp. 65-116.

3 WeInZIERL, E. (ed.): "Religiöser Fatalismus und das Problem des Úbels", en: Der Modernismus. Beiträge zu seiner Erforschung, Styria: Graz 1974, pp. 369-409.
} 
Otro factor es la amabilidad poco frecuente que el autor muestra en su uso de la lógica simbólica, ya que para todas las fórmulas ofrece una traducción en lenguaje ordinario. A esto se añade que el estudio nos presenta un caso concreto de aplicación de esta lógica que de verdad lleva a obtener una luz sobre una cuestión existencial. Por último, ver cómo Tomás de Aquino resiste tal análisis es una experiencia nada desdeñable.

Me permito pues hacer dos consideraciones que pueden facilitar la comprensión del texto de Weingartner. De la primera no tendrá ninguna necesidad quien esté familiarizado con las funciones proposicionales. La segunda es una contextualización de carácter cultural sobre lo que entendemos por algunos de los términos usados en este campo.

\section{Las funciones proposicionales.}

El punto central de este artículo es de una extremada sencillez si se cuenta con una buena comprensión de su mecanismo desde la naturaleza de las correspondientes funciones proposicionales. Las más conocidas son quizá las proposiciones categóricas, las que en el siglo XIII.recibieron la nomenclatura A, E, I, O, y que cualquier manual de lógica suele explicar. Es bien conocido el cuadro de sus oposiciones, del que se conservan dibujos antiquísimos:

$$
\begin{array}{ll}
\text { todo } F \text { es } G(A) & \text { ningún } F \text { es } G(E) \\
\text { algún } F \text { es } G(I) & \text { algún } F \text { no es } G(O)
\end{array}
$$

Conviene recordar que la negación de una proposición es su contradictoria. Dos proposiciones contradictorias son necesariamente una verdadera y otra falsa (a menos que intervenga la analogía, pero aquí esto no se va a presentar). La contradictoria de cada una de estas proposiciones es la qué se encuentra èn la esquina opuesta del cuadro. Dos proposiciones que se encuentran a la misma altura no 
son contradictorias sino contrarias, y no son necesariamente una verdadera y otra falsa.

En las proposiciones categóricas tenemos dos funciones, que en este caso se llaman cuantificadores: "todo" y "alguno". Sin embargo, basta uno de los dos, más un uso adecuado de la negación, para expresar el contenido de las cuatro esquinas del cuadro. La negación puede estar antes o después del cuantificador, según niegue la función (el cuantificador) o la proposición; se suele hablar, respectivamente, de negación externa y negación interna. Siempre se puede pasar la negación de un lado al otro, con tal de cambiar el cuantificador. $\mathrm{O}$, cuando no hay ninguna negación, se puede cambiar el cuantificador y colocar dos negaciones, una antes y otra después. Voy a usar ahora los cuantificadores en plural porque creo que eso facilita la comprensión. "Algunos" es lo mismo que "no todos no"; "todos" es lo mismo que "no algunos no" (aunque esto nos resulta más lejano del lenguaje corriente). "No todos" es lo mismo que "algunos no", y "no algunos" lo mismo que "todos no". En este cuadro tenemos un tercer término, "ninguno", que es lo mismo que "todos no". En latín existe una cadena interesante de términos (adjetivos o pronombres) que respeta este uso de la negación: "ullus" significa alguno, "nullus" significa ninguno, y "nonnullus" significa, otra vez, alguno. El cuadro resulta como sigue (uso "es falso" en lugares donde la negación externa suena poco natural):

todo $\mathrm{F}$ es $\mathrm{G}$

(= es falso que algún $F$ no sea $G$ ) ningún $\mathrm{F}$ es $\mathrm{G}$

(= todo $F$ no es $G$ )

(= es falso que algún $F$ sea $G$ ) (nullus)

algún $F$ no es $G$

(= no todo $F$ es $G$ ) algún $\mathrm{F}$ es $\mathrm{G}$

( $=$ no todo $F$ no es $G$ )

(ullus; nonnullus) 
Esto nos debería ayudar a entender las funciones proposicionales que se manejarán aquí, que son las de la voluntad o el querer. Si en la esquina superior izquierda colocamos "quiere", su negación ("no quiere") deberá ocupar la esquina inferior derecha. Debajo de "quiere" habrá que colocar "no quiere que no" (o sea, negación antes y después), y en la esquina faltante, "quiere que no".

$\mathrm{X}$ quiere que $\mathrm{p}$

$\mathrm{X}$ no quiere que no $\mathrm{p}$
$\mathrm{X}$ quiere que no $\mathrm{p}$

$\mathrm{X}$ no quiere que $\mathrm{p}$

Si queremos tener dos funciones, como las teniamös en el primer cuadro, el verbo que hay que añadir es "permite". Esto es muy importante aquí, porque el tema constante del artículo de Weingartner es la comprensión de la diferencia entre la voluntad y la permisión divinas, entre lo que Dios quiere y lo que Dios permite. Como la permisión pertenece a este cuadro, que se puede llamar cuadro de la voluntad, es razonable que la permisión sea vista como un tipo de voluntad (la "voluntad permisiva"), pero, propiamente, lo que se permite no se quiere. El cuadro, pues, queda como sigue:

$\mathrm{X}$ quiere que $\mathrm{p}$

(= no permite que no $\mathrm{p}$ )

$\mathrm{X}$ permite que $\mathrm{p}$

(= no quiere que no $p$ )
$\mathrm{X}$ quiere que no $\mathrm{p}$

(= no permite que $p$ )

$X$ no quiere que $\mathrm{p}$

(= permite que no $\mathrm{p}$ )

Algunas equivalencias pueden sonar extrañas, pero es ésa precisamente la cuestión. Por una parte, en el artículo se habla de Dios, donde no hay distancia entre el querer y el poder (como es el caso del hombre; por eso en algunos casos nos sonaría más natural 
"no acepta" que "no permite", que lleva a pensar en la eficacia del impedir). Por otra, no hay una plena coincidencia entre las leyes de la lógica y las del lenguaje ordinario, cosa que analiza Weingartner.

Antes de señalar el punto central voy a presentar un tercer cuadro, que es el de las modalidades:

es necesario que $p$

(= no es posible que no $p$ ) es imposible que $\mathrm{p}$

(= es necesario que no $p$ )

(= no es posible que $\mathrm{p}$ )

no es necesario que $\dot{\mathrm{p}}$

(= es posible que no $\mathrm{p}$ )

(= no es imposible que no $p$ )

Aquí, como en las proposiciones categóricas, aparece un tercer término ("es imposible"). De hecho también hay un cuarto, "es contingente" -que iría en la esquina inferior derecha-, pero no lo coloco en el cuadro porque se trata de una cuestión controvertida que no facilitaria aquí las cosas. Este cuadro nos será más útil si lo formulamos con los verbos "deber" y "poder". Hay varias posibilidades, pero escojo la que me parece más próxima a la sintaxis del lenguaje corriente:

$\mathrm{p}$ debe ser

(= $\mathrm{p}$ no puede no ser)

$p$ puede ser

(= $\mathrm{p}$ no debe no ser) $\mathrm{p}$ no puede ser

(= $\mathrm{p}$ debe no ser)

$\mathrm{p}$ no debe ser

(= p puede no ser) 
El punto central del artículo de Weingartner consiste en señalar un error muy común en la comprensión del cuadro de la voluntad. Cuando queremos que algo no suceda, solemos decir "no quiero que suceda". Suena muy raro decir "quiero que no suceda". No pretendo llegar a la conclusión de que hablamos mal, porque aquí lo más procedente es concluir: "así se dice". Lo mismo se ha de decir de algunas dobles negaciones en español ("no hay nadie", "no entendi nada") y de infinidad de expresiones que, tomadas a la letra, contradicen nuestros conocimientos sobre aquello mismo de lo que hablamos, que pueden ser realidades cósmicas ("está saliendo el sol"), las leyes de Dios ("le pusieron una golpiza como Dios manda"), o la anatomia humana ("échale un ojo al bebé").

El problema que nos ocupa reside en que alli la formulación sí suele crear confusión en el pensamiento mismo. Decir que el sol sale y se mete no pone en peligro nuestra concepción copernicana del sistema solar; habrá quien esté convencido de que Dios manda dar golpizas ( $\mathrm{y}$ hasta poner bombas), pero no es serio pensar que eso dependa de la expresión mencionada; $y$, en fin, negarse a arrojar un globo ocular no pasa de ser un chiste. En cambio, nuestro habitual modo de expresar un querer negativo ("quiero que no") como la negación de un querer ("no quiero") si nos empuja a malentender la voluntad. Y esto ya no es una particularidad del español como las dobles negaciones (normales también en las otras lenguas latinas, aunque prohibidísimas en inglés y en alemán ${ }^{4}$ ) sino que se trata de algo bastante universal. Con igual familiaridad se preocupan por este problema Weingartner, que escribe en alemán, y Santo Tomás, que escribia en latín.

Dado que el tema del artículo de Weingartner es precisamente éste, me limitaré a ilustrar lo natural que nos resulta expresarnos así, acudiendo a la comparación con las otras funciones proposicionales. El mecanismo consiste en colocarle a la función la negación que propiamente corresponde a la proposición, o sea, usar una negación externa donde iría una negación interna.

${ }^{4}$ En griego clásico también son normales. Ignoro qué sucede en el moderno. Son igualmente normales en las lenguas eslavas. 
En el segundo cuadro de las modalidades (el que usa los verbos deber / poder), sucede lo mismo. Decimos regularmente "no debes" para expresar una prohibición. Y cuando queremos decir que alguien no tiene una obligación, o sea que "no debe", nos encontramos con dificultades, y tenemos que asegurar el sentido con el tono, o diciéndolo con otras palabras.

Con las proposiciones categóricas no parece suceder lo mismo, al menos en español. Hay otros problemas, pero no éste. Habría que ver qué pasa en otros idiomas. Por lo pronto, me llama la atención que la versión latina del relato de la Anunciación (evangelio de San Lucas, 1,37) diga: "Non erit impossibile apud Deum omne verbum". Si mantenemos las funciones y las negaciones como están, la traducción sería "Para Dios no todo es imposible", pero es claro que el sentido es: "Para Dios nada es imposible"s.

Si hubiera plena conciencia de las relaciones entre las dos expresiones del lado derecho de los cuadros (es decir, entre la negación externa y la negación interna), el uso corriente podría explicarse como una figura retórica que cabe llamar "quedarse corto", lo contrario de la hipérbole o exageración, que en otros idiomas tiene un nombre especifico (understatement, Untertreibung) mientras en español habría que acudir al término meiosis, que es muy técnico. Como la esquina inferior derecha del cuadro se sigue de la superior derecha (es decir, si es verdadera la superior lo es necesariamente la inferior ${ }^{6}$ ), afirmar la inferior pudiéndose afirmar la superior es "quedarse corto". Buen ejemplo sería el del evangelio de San Lucas, sólo que no me imagino a San Gabriel expresándose con understatements, que me parece un tono castigador más propio de James Bond que de un arcángel. De la misma manera, cabe decirle a

${ }^{5}$ Tengo a la mano las siguientes traducciones: "Nada hay imposible para Dios"; "No habrá para Dios cosa imposible"; "No hay nada imposible para Dios". En griego el texto tiene la misma estructura que en latin. En italiano existen fómulas proverbiales, de sabor arcaico, que usan esa misma posición de la negación: "Tutti non possono aver la casa in piazza"; "Tutti non possono stare a messa vicino al prete"; "Gioia e sciagura sempre non dura"; "Tutto il male non vien per nuocere".

${ }^{6}$ Esto, bajo ciertas condiciones, que no es dificil que se den. En las proposiciones categóricas la condición es la existencia. 
alguien "No tienes obligación de ahorcar a tu suegra", cosa que, dicha así; tiene todas. las características de la meiosis, pero, expresada con el verbo "deber", sonará a la simple formulación de una prohibición: "no debes ahorcar a tu suegra"?

\section{Fórmulas fatalistas}

El autor dice en varios momentos que, aunque la tesis del fatalismo religioso no. es compatible con las religiones que creen en un Dios bueno y perfecto en grado sumo, algunas personas religiosas la han sostenido. Me parece que se trata de otro caso de distancia entre el sentido literal de una expresión y el pensamiento que se quiere expresar. Que se pueda dar uńa auténtica postura fatalista en un creyente es algo que no pienso abordar aquí. A modo de ayuda para la comprensión del artículo creo que basta con ilustrar la posibilidad de que alguien se exprese de modo fatalista sin serlo:

Este fatalismo es muy fácil de escuchar. Si se reúne un buen número de formulaciones de aceptación de la voluntad de Dios,: se verá que un porcentaje elevado es fatalista a la letra. Mẹnos claro me parece que lo sea realmente. Decir "que se haga (se cumpla) la voluntad de Dios" suele ser una fórmula conscientemente amplia, donde no se pretende tener claro qué es lo positivamente querido por Dios. Es muy frecuente la fórmula condicional "si es la voluntad de Dios..." o "si Dios lo quiso", respectivamente para pedir que algo

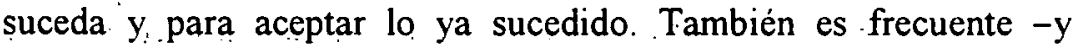
Weingartner lo menciona al final de su artículo- la renuncia. a entender, declarando al mismo tiempo que "Dios sabe más", "Dios sabe por qué", etc.

7 Una clara meiosis con el cuadro de la voluntad, pero con la columia de la izquierda, seria expresar el querer con la negación de un verbo què expresa negación del permitir: "oponerse". Decir "no me opongo" para expresar un deseo adquiere fácilmente un tono irónico o jocoso. Ignoro qué diría un jurista sobre la validez de esta fórmula como expresión del consentimiento matrimonial: "¿Acepta usted a...? - No me opongo". Quizá no es ésa la mejor sede para quedarse uno corto. 
Para una formulación más rigurosa, muchas veces parecería conveniente sustituir querer por permitir, pero no me parece estrictamente necesario, ya que es muy probable que lo que se tiene en mente sea correcto. Aquí puede ser útil recordar el carácter no mágico de la oración. Es normal que un creyente no considere decisiva la corrección exacta de la fórmula usada, ya que quien la recibe no es un lector digital ("sensitive to misspelling", en terminología informática) sino un ser inteligente. Rezar por una persona no significa apoyar todo lo que esa persona trae entre manos, tal como lo trae (por eso rezar públicamente por los gobernantes no es hacer política). Ciertamente hay deformaciones, que son eso: ignorancias, corrupciones, casos de superstición. Por eso no falta quien se horrorice de haber rezado por un vivo dentro de una oración por los difuntos, o quien piense que la oración del sacerdote concede la salvación de un alma, o quien crea que un error al formular la petición hará que no se obtenga lo que realmente se queria. Abundantes ejemplos de deformaciones nos ofrece Juan Rulfo, como aquel episodio del sacerdote que, concluido un funeral, omite la bendición: “- ¡Padre, queremos que nos lo bendiga! - ¡No! -dijo moviendo negativamente la cabeza-. No lo haré. Fue un mal hombre y no entrará al Reino de los Cielos. Dios me tomará a mal que interceda por él" (Pedro Páramo).

Está claro que habria que distinguir entre las sensibilidades de las diversas religiones monoteístas $\mathrm{y}$, dentro del cristianismo, de las diversas confesiones, pero esto es excesivo para una introducción como la presente ${ }^{8}$. Sólo quisiera señalar, antes de terminar, que en el cristianismo es muy'fuerte la presencia de un peculiar modo de concebir las relaciones de Dios con el mal, según la cual la conjunción de su bondad y su omnipotencia se manifiesta no tanto en el modo de evitar los males cuanto en el modo de sacar bienes de los males.

\footnotetext{
${ }^{8}$ Cuando expongo este tema en la universidad, los alumnos que en sus paises tienen habitual contacto con musulmanes observan siempre que éstos parecen poco sensibles a la distinción entre voluntad y permisión en Dios. Comentarios semejantes suelen hacerse sobre el calvinismo.
} 
Copyright of Tópicos. Revista de Filosofía is the property of Universidad Panamericana and its content may not be copied or emailed to multiple sites or posted to a listserv without the copyright holder's express written permission. However, users may print, download, or email articles for individual use. 